\title{
Cytotoxic Lactones from the Pericarps of Litsea japonica
}

\author{
Quynh-Mai Thi Ngo ${ }^{\dagger}$, Thao Quyen Cao ${ }^{\dagger}$, Mi Hee Woo, and Byung Sun Min* \\ College of Pharmacy, Drug Research and Development Center, Daegu Catholic University, \\ Gyeongbuk 38430, Republic of Korea.
}

\begin{abstract}
From the pericarps of Litsea japonica (Thunb.) Jussieu, eighteen butanolide derivatives (1 - 18) were evaluated for their cytotoxic activity against HeLa, HL-60, and MCF-7 cells. Compounds 1 - 9 with 2-alkylidene3-hydroxy-4-methylbutanolides structure exhibited cytotoxic activities against cancer-cell lines. Among them, compound 8 (litsenolide $\mathrm{D}_{2}$ ) exhibited the most potent cytotoxicity against the tested cell lines, including HeLa, HL-60, and MCF-7, with $\mathrm{IC}_{50}$ values of $17.6 \pm 1.3,4.2 \pm 0.2$, and $12.8 \pm 0.0 \mu \mathrm{M}$, respectively. Compound 8 induced apoptosis in a dose-dependent manner. Annexin V/Propidium Iodide (PI) double staining confirmed that 8 effectively induced apoptosis in MCF-7 cells. To the best of our knowledge, we have reported cytotoxic activity of butanolides from L. japonica against these cancer-cell lines for the first time.
\end{abstract}

Keywords - Litsea japonica, Lauraceae, butanolide, lactone, cytotoxic activity, apoptosis

\section{Introduction}

Litsea japonica (Thunb.) Jussieu (Lauraceae) is grown in Korea and Japan. In Korea, it has been consumed as a vegetable. In traditional medicine, Litsea species have been used to treat diarrhea, rheumatism, bone fractures, snake bites, influenza, stomach ache, pain, and other disorders. ${ }^{1}$ Previous studies on these plants reported the presence of alkaloids, ${ }^{2}$ flavonoids, ${ }^{3}$ terpenes, ${ }^{4}$ lignans, ${ }^{5}$ fatty acids, ${ }^{6}$ essential oils, ${ }^{4}$ butenolactones, ${ }^{7}$ and butanolides. ${ }^{1}$ Several cytotoxic butanolides were isolated from Litsea species. Eight butanolides from $L$. akoensis were investigated and showed cytotoxic activity against P-388, KB16, A549, and HT-29 cancer-cell lines. ${ }^{8}$ Some butanolides from $L$. acutivena showed significant cytotoxic effects on P-388, A549, and HT-29 cancer-cell lines in vitro. ${ }^{9}$ Licunolide $\mathrm{B}$, a butanolide with a $\mathrm{C}_{10}$-side chain from $L$. acuminate, also showed significant cytotoxicity against the HeLa cell line with $\mathrm{IC}_{50}$ value of $0.47 \mu \mathrm{g} / \mathrm{mL}{ }^{10}$ In our previous study, eighteen butanolide derivatives were isolated from the pericarps of $L$. japonica, structurally elucidated, and investigated for anti-inflammatory activity. ${ }^{11}$ Our data indicated that 2-alkylidene-3-hydroxy-4-methylbutanolide

\footnotetext{
*Author for correspondence

Byung Sun Min, College of Pharmacy, Drug Research and Development Center, Daegu Catholic University, Gyeongbuk 38430, Republic of Korea.

Tel: +82-53-850-3613; E-mail: bsmin@cu.ac.kr

${ }^{\dagger}$ These authors contributed equally to this work
}

derivatives from $L$. japonica exhibited potent inhibitory effects on inducible nitric oxide synthase (iNOS) and cyclooxygenase-2 (COX-2) expression. In our continuing research, eighteen isolated butanolides were investigated for their cytotoxic activity. Herein, we report their cytotoxic effects on HeLa (human cervix carcinoma), MCF-7 (breast cancer), and HL-60 (human myeloid leukemia) cancer-cell lines. The apoptosis-inducing effect on MCF-7 cell line was also reported in this paper.

\section{Experimental}

Plant material - The pericarps of L. japonica Jussieu (Lauraceae) used in this study were collected in Jeju islands, Republic of Korea in June 2016 and identified by Professor Byung Sun Min. A voucher specimen (CUD1517-1) was deposited at the Herbarium of the College of Pharmacy, Daegu Catholic University, Korea.

Isolation of tested compounds - Compounds $\mathbf{1}$ - 18 were isolated from the pericarps of $L$. japonica described in our previous study. ${ }^{11}$ Their structures are shown in Fig. 1.

In vitro cytotoxic activity - The cytotoxic activity assay was carried out using the 3-(4,5-dimethylthiazol-2yl)-2,5-diphenyltetrazolium bromide (MTT) assay. ${ }^{13}$ Hela, MCF-7, and HL-60 cancer-cells were cultured in Dulbecco's modified Eagle's medium (DMEM)/F-12 with $15 \mathrm{mM}$ HEPES buffer, L-glutamine, and pyridoxine hydrochloride supplemented with $10 \%$ fetal bovine serum and $1 \%$ penicillin-streptomycin in a 96-well plate at a density of 6 


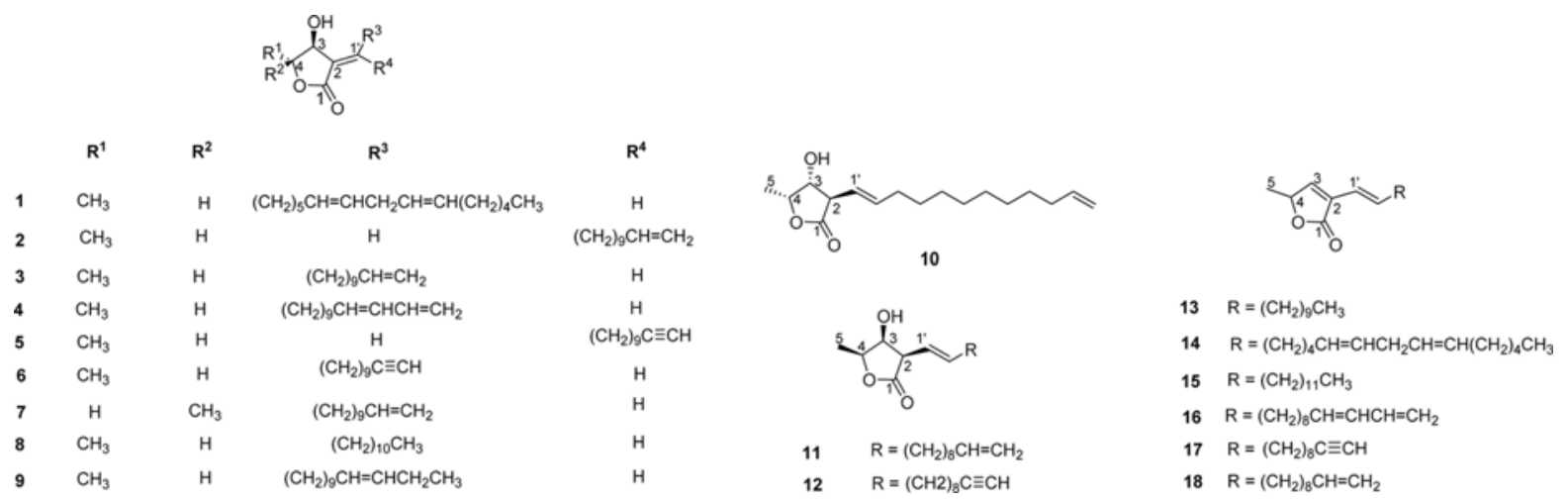

Fig. 1. The structures of compounds $\mathbf{1}$ - $\mathbf{1 8}$ from the pericarps of Litsea japonica.

$\times 10^{4}$ cells $/ \mathrm{mL} .^{12}$ After reaching confluence $\left(2 \times 10^{5}\right.$ cells/ $\mathrm{mL}$ ), the cells were treated with the compounds. The compounds were dissolved in dimethylsulfoxide (DMSO) and the final concentration of DMSO was less than $0.1 \%$ $(\mathrm{v} / \mathrm{v})$. Various concentrations of tested compounds were prepared with serial dilutions. The experiment was allowed to proceed for $48 \mathrm{~h}$ at $37^{\circ} \mathrm{C}$ in a humidified $5 \%$ $\mathrm{CO}_{2}$ atmosphere. At the end of this period, supernatants were discarded. To minimize the interference of supernatant residue, the adherent cells were washed twice with Dulbecco's phosphate buffered saline (DPBS), and then $20 \mu \mathrm{L}$ of MTT stock solution $(5 \mathrm{mg} / \mathrm{mL})$ was added to each well and the plates were further incubated for $3 \mathrm{~h}$ at $37^{\circ} \mathrm{C}$. DMSO $(100 \mu \mathrm{L})$ was added to each well to solubilize the water-insoluble purple formazan crystals. After $1 \mathrm{~h}$, the absorbance was measured at $570 \mathrm{~nm}$ with a microplate reader. Adriamycin, a commercial standard anticancer agent, was used as a positive control. The $50 \%$ reduction in cell number relative to the control $\left(\mathrm{IC}_{50}\right)$ was estimated visually. The results are presented as mean \pm standard error of mean (SEM). ${ }^{18}$

Annexin-V and PI dual staining assay-Dual propidium iodide (PI) and annexin-V labeling for cell death was carried out using an Annexin-V-FLUOS staining kit in accordance with the manufacturer's instructions (BD Biosciences, CA, USA). Cells were harvested after incubation with compound $\mathbf{8}$, washed with PBS ( $\mathrm{pH}$ 7.4), centrifuged, and stained with annexin V-FITC and $2 \mu \mathrm{g} /$ $\mathrm{mL}$ PI in binding buffer (10 mM HEPES, $\mathrm{pH} 7.4 ; 140$ $\mathrm{mM} \mathrm{NaCl}, 2.5 \mathrm{mM} \mathrm{CaCl}_{2}$ ) for $15 \mathrm{~min}$ at $37^{\circ} \mathrm{C}$ in the dark. The samples were analyzed by flow cytometry using a FACScan flow cytometer, and the CellQuest software was used to analyze the data (Becton-Dickinson). ${ }^{19}$

\section{Results and Discussion}

From the $n$-hexane soluble fraction, eighteen butanolides
Table 1. Cytotoxic activities of compounds $\mathbf{1}$ - $\mathbf{1 8}$ against Hela, HL-60, and MCF-7 cell lines

\begin{tabular}{cccc}
\hline \hline \multirow{2}{*}{ Compds } & \multicolumn{3}{c}{$\mathrm{IC}_{50}, \mu \mathrm{M}^{\mathrm{a}}$} \\
\cline { 2 - 4 } & HeLa & \multicolumn{1}{c}{ HL-60 } & MCF-7 \\
\hline 1 & $47.0 \pm 0.2$ & \pm 0.4 & $38.7 \pm 0.3$ \\
3 & $18.4 \pm 0.8$ & $5.5 \pm 0.6$ & $38.2 \pm 0.5$ \\
4 & $45.2 \pm 0.9$ & $22.1 \pm 1.8$ & $72.2 \pm 0.6$ \\
5 & $34.2 \pm 0.4$ & $14.0 \pm 0.6$ & $24.4 \pm 0.7$ \\
6 & $80.3 \pm 2.0$ & $26.3 \pm 0.0$ & $67.5 \pm 0.1$ \\
7 & 100 & $29.6 \pm 0.8$ & $>100$ \\
8 & $27.7 \pm 0.2$ & $11.2 \pm 1.5$ & $27.2 \pm 0.2$ \\
9 & $17.6 \pm 1.3$ & $4.2 \pm 0.2$ & $12.8 \pm 0.0$ \\
10 & $19.1 \pm 1.1$ & $8.1 \pm 0.3$ & $22.9 \pm 1.1$ \\
11 & 100 & $23.2 \pm 0.5$ & $>100$ \\
12 & $54.5 \pm 0.3$ & $47.6 \pm 0.7$ & $>100$ \\
13 & - & $30.2 \pm 0.9$ & $>100$ \\
14 & 100 & $37.0 \pm 1.2$ & $>100$ \\
15 & $95.4 \pm 0.3$ & $28.3 \pm 1.6$ & $>100$ \\
16 & - & - & - \\
17 & - & $27.4 \pm 1.3$ & $>100$ \\
18 & - & $32.6 \pm 0.9$ & - \\
Adriamycin ${ }^{\mathrm{b}}$ & $0.67 \pm 0.5$ & $0.24 \pm 0.06$ & $3.4 \pm 0.2$ \\
\hline The & & 54.6 &
\end{tabular}

a The results are presented as mean $\pm \operatorname{SEM}(\mathrm{n}=3)$.

${ }^{\mathrm{b}}$ Positive control.

(1-18) were isolated and structurally elucidated as litsenolide $F_{1}(\mathbf{1}),{ }^{11}$ litsenolide $A_{1}(2),{ }^{14}$ litsenolide $A_{2}$ (3) ${ }_{14}^{14}$ litseakolide B (4),${ }^{8}$ litsenolide $\mathrm{B}_{1}(\mathbf{5}),{ }^{14}$ litsenolide $\mathrm{B}_{2}$ (6), ${ }^{14}$ lincomolide C (7),${ }^{15}$ litsenolide $\mathrm{D}_{2}(\mathbf{8}),{ }^{16}$ litsenolide $\mathrm{E}_{2}(\mathbf{9}),{ }^{16}$ lisealactone $\mathrm{H}_{1}(\mathbf{1 0}),{ }^{11}$ lisealactone $\mathrm{H}_{2}(\mathbf{1 1}),{ }^{11}$ litsealactone B (12), ${ }^{7}$ akolactone D (13), ${ }^{11}$ akolactone $\mathrm{E}$ (14), ${ }^{11}$ akolactone A (15), ${ }^{8}$ akolactone B (16), ${ }^{8}$ hamabiwalactone A (17) ${ }^{16}$ and hamabiwalactone B (18) ${ }^{16}$ (Fig. 1).

Eighteen isolated butanolide derivatives $(\mathbf{1}$ - 18) were examined for their cytotoxic effects on HeLa, MCF-7, and HL-60 cancer-cell lines. The $\mathrm{IC}_{50}$ values in Table 1 
show that HL-60 cells were more sensitive than the other two cell lines in the presence of the tested compounds. Among these compounds, compounds 1-9 with 2alkylidene-3-hydroxy-4-methylbutanolide structure exhibited cytotoxic activities against the tested cancer-cell lines, with $\mathrm{IC}_{50}$ less than $50 \mu \mathrm{M}$. Meanwhile, compounds 10 $\mathbf{1 8}$ did not significantly inhibit the HeLa and MCF-7 cell lines. They had cytotoxic effects only on HL-60 cells, with $\mathrm{IC}_{50}$ ranging from 23.2 to $54.9 \mu \mathrm{M}$. Therefore, the 2alkylidene-3-hydroxy-4-methylbutanolide structure might be important for cytotoxic activity. The structure-activity relationship (SAR) for cytotoxic activity closely matched that for anti-inflammatory effect in our previous study. ${ }^{11}$ Among the isolated compounds, $\mathbf{3}, \mathbf{6}$, and $\mathbf{8}$ were similar in structures. They have the same $3 S, 4 R$ configuration and the same length of side chain, with 12 carbons. From bioactivity comparison, their cytotoxicity on the three cancer-cell lines was in the order of $\mathbf{8}>\mathbf{3}>\mathbf{6}$. Compound 8 (litsenolide $\mathrm{D}_{2}$ ), a butanolide with the $\mathrm{C}_{12}$ saturated chain, exhibited the most potent cytotoxicity against the tested cancer-cell lines, HeLa, HL-60, and MCF-7, with $\mathrm{IC}_{50}$ values of $17.6 \pm 1.3,4.2 \pm 0.2$, and $12.8 \pm 0.0 \mu \mathrm{M}$, respectively. The terminal vinyl group in $\mathbf{3}$ decreased its activity, with $\mathrm{IC}_{50}$ values much lower than those of 8 . Furthermore, 6, with a triple bond at C-11 instead of a double bond as in $\mathbf{3}$, showed no cytotoxic activity against the HeLa and MCF-7 cell lines, and moderate activity against HL-60 cells, with $\mathrm{IC}_{50}$ value of $29.6 \mu \mathrm{M}$, sevenfold lower than that of $\mathbf{8}$. In addition, a cytotoxic butanolide with a $\mathrm{C}_{10}$ saturated aliphatic side chain from L. acuminata, licunolide $\mathrm{B}(\mathrm{MW}=254.37)$ was reported with an $\mathrm{IC}_{50}$ value of $0.47 \mu \mathrm{g} / \mathrm{mL}(1.85 \mu \mathrm{M})$ in HeLa cells. ${ }^{10}$ These results indicated that a saturated aliphatic chain might play a key role in the cytotoxic activity of butanolide derivatives. On the other hand, a butanolide with a $3 S, 4 S$ configuration, compound 7 , exhibited twofold more potent activity than its $3 S, 4 R$ derivative, compound 3. This result indicates that the $3 S, 4 S$ configuration might be beneficial for cytotoxic activity. Moreover, the $Z$-alkylidenyl derivatives $(\mathbf{2}, \mathbf{5})$ exhibited more potent inhibition on cancer-cell viability than did the corresponding $E$-alkylidenyl derivatives $(\mathbf{3}, \mathbf{6})$, suggesting that the $Z$-form configuration of the tri-substituted double bond might increase the cytotoxic effect of butanolides. Therefore, a 2-Z-alkylidene-3S-hydroxy-4R-methylbutanolide with a saturated aliphatic chain is beneficial for cytotoxic ability. The structure-activity relationship (SAR) of butanolides on cytotoxic effect is summarized in Fig. 2.

Moreover, approximately one-third of the women with breast cancer developed metastases and ultimately died of

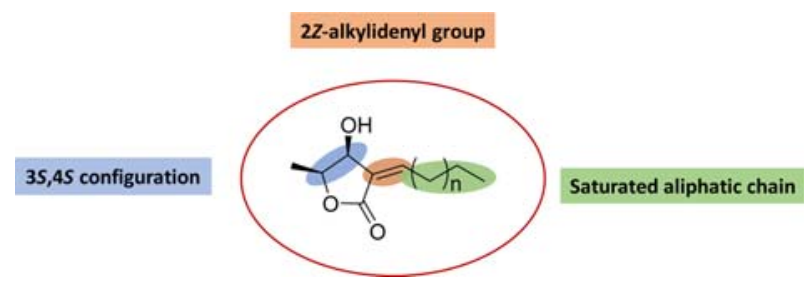

Fig. 2. SAR summary of butanonolide derivatives.

the disease. ${ }^{20}$ The growth and survival of cancer cells is correlated with a reduced level of genetically programmed cell death; the apoptosis. Recently, the relationship between apoptosis and cancer has been emphasized, with increasing evidence suggesting that the related processes of neoplastic transformation, progression and metastasis involve the alteration of normal apoptotic pathways. Apoptosis provides a number of clues with respect to effective anticancer therapy, and many chemotherapeutic agents reportedly exert their antitumor effects by inducing apoptosis in cancer cells. Considerable attention has been devoted to the sequence of events referred to as apoptotic cell death and the role of this process in mediation of the lethal effects of the diverse antineoplastic agents. ${ }^{21,22}$ In this study, the MCF-7 cell line was treated with $8(1,3,10$ and $30 \mu \mathrm{M}$ ) for $24 \mathrm{~h}$, stained with annexin V-FLUOS and PI, and analyzed by flow cytometry. ${ }^{23}$ The number of cells in the early and late stages of apoptosis significantly increased in a dose-dependent manner. Compound $\mathbf{8}$ induced apoptosis in MCF-7 cells, especially late stage apoptosis. The percentage of apoptotic cells, including early and late stage of apoptosis, increased from $0 \%$ (control) to appropriate $13 \%$ in response to 8 treatment. This result suggested that the treatment with $\mathbf{8}$ induced apoptosis in MCF-7 cells (Fig. 3).

Previously, butanolides isolated from L. japonica have been shown to have potent anti-inflammatory effects. In particular, litsenolide $\mathrm{A}_{2}(\mathbf{3})$ and litsenolide $\mathrm{B}_{2}(\mathbf{6})$, two main active compounds from the fruits of $L$. japonicum, inhibit the production of LPS-induced $\mathrm{NO}$ and $\mathrm{PGE}_{2}$, proinflammatory cytokine, in RAW264.7 cells in a dosedependent manner. The mechanism of these effects was shown to be related to suppressing the NF-KB and MAPK signaling pathway. ${ }^{17}$ Akolactone $\mathrm{B}(\mathbf{1 6})$ and hamabiwalactone B (18) were reported to have significant inhibitory activity in an in vitro anti-complement assay, which is a useful modulation in researching anti-inflammatory drugs. ${ }^{7}$ In addition, the anti-inflammatory activity of the eighteen butanolide derivatives from the fruits of $L$. japonica was previously evaluated in our study. ${ }^{11}$ Among them, litsenolide $\mathrm{A}_{2}$ (3) significantly inhibited NO 

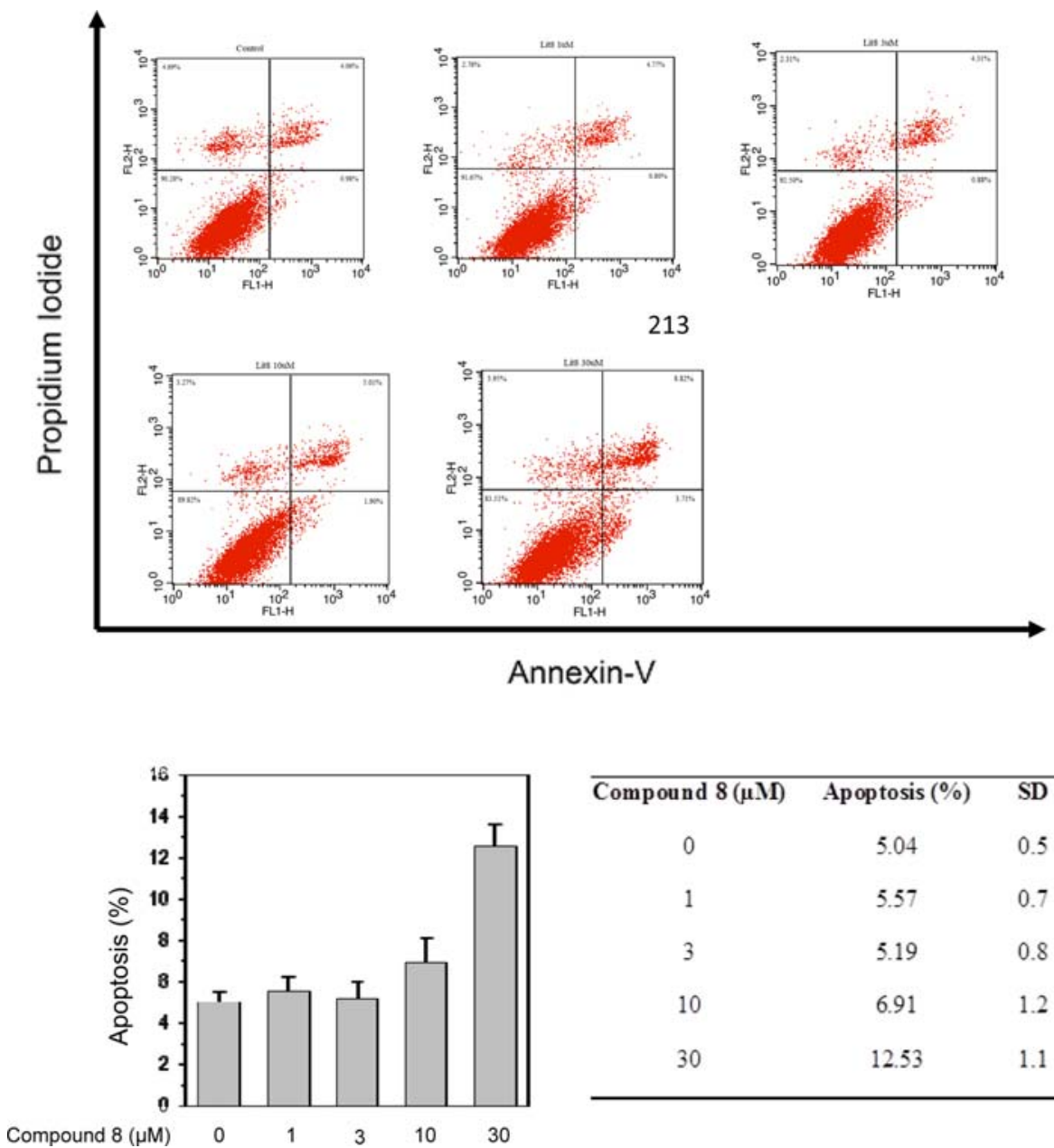

\begin{tabular}{ccc}
\hline Compound 8 $(\mu \mathrm{M})$ & Apoptosis (\%) & SD \\
0 & 5.04 & 0.5 \\
1 & 5.57 & 0.7 \\
3 & 5.19 & 0.8 \\
10 & 6.91 & 1.2 \\
30 & 12.53 & 1.1 \\
\hline
\end{tabular}

Fig. 3. Flow cytometric analysis of compound 8 -induced apoptosis in MCF-7 cell using annexin-V-FLUOS/PI. Cells $\left(1 \times 10^{6}\right.$ cells $)$ were incubated with indicated concentration of $\mathbf{8}$ for $24 \mathrm{~h}$ and stained with annexin-V-FLUOS/PI to analysis apoptosis and necrotic cell populations. Cells in the lower right quadrant represented apoptosis and upper right quadrant. Data are representative of one of three similar experiments.

production and iNOS and COX-2 expression in LPSinduced RAW264.7 cells. However, cytotoxic activity of L. japonica lactones against these three cancer-cell lines has been reported for the first time to the best of our knowledge. Among the isolated compounds, the 2-Zalkylidene-3-hydroxy-4-methylbutanolide moiety with a saturated long aliphatic side chain in butanolide derivatives was shown to be the main pharmacophore. Therefore, natural product isolation or synthesis of these target derivatives should be done to develop new anti-cancer agents.

\section{Acknowledgements}

This study was supported by the research grant from Daegu Catholic University in 2018 (Grant No. DCU20181057).

\section{References}

(1) Wang, Y. S.; Wen, Z. Q.; Li, B. T.; Zhang, H. B.; Yang, J. H. J. Ethnopharmacol. 2016, 181, 66-107.

(2) Lee, S. S.; Lin, Y. J.; Chen, C. K.; Liu, K. C. S.; Chen, C. H. J. Nat. Prod. 1993, 56, 1971-1976.

(3) Dong, S.; Tong, X.; Li, J.; Huang, C.; Hu, C.; Jiao, H.; Gu, Y. Neural. Regen. Res. 2013, 8, 3193-3202.

(4) Yang, Y.; Jiang, J.; Qimei, L.; Yan, X.; Zhao, J.; Yuan, H.; Qin, Z.; Wang, M. Molecules 2010, 15, 7075-7082.

(5) Wang, L.; Zhao, J. F.; Zeng, X. H.; Xie, M. J.; Yang, X. D.; Zhang, H. B.; Li, L. J. Asian Nat. Prod. Res. 2009, 11, 1028-1031.

(6) Tsai, I. L.; Jeng, Y. F.; Duh, C. Y.; Chen, I. S. J. Chin. Pharm. Sci. 2001, 53, 291-301.

(7) Min, B. S.; Lee, S. Y.; Kim, J. H.; Kwon, O. K.; Park, B. Y.; An, R. B.; Lee, J. K.; Moon, H. I.; Kim, T. J.; Kim, Y. H.; Joung, H.; Lee, H. K. J. Nat. Prod. 2003, 66, 1388-1390.

(8) Chen, I. S.; Lai-Yaun, I. L.; Duh, C. Y.; Tsai, I. L. Phytochemistry 1998, 49, 745-750.

(9) Cheng, H. I.; Lin, W. Y.; Duh, C. Y.; Lee, K. H.; Tsai, I. L.; Chen, I. S. J. Nat. Prod. 2001, 64, 1502-1505. 
(10) Tanaka, H.; Takaya, Y.; Toyoda, J.; Yasuda, T.; Sato, M.; Murata, J.; Murata, H.; Kaburagi, K.; Iida, O.; Sugimura, K.; Sakai, E. Phytochem. Lett. 2015, 11, 32-36.

(11) Ngo, Q. T.; Cao, T. Q.; Tran, P. L.; Kim, J. A.; Seo, S. T.; Kim, J. C.; Woo, M. H.; Lee, J. H.; Min, B. S. Bioorg. Med. Chem. Lett. 2018, 28, 2109-2115.

(12) Guon, T. E.; Chung, H. S. Nat. Prod. Sci. 2017, 23, 227-234.

(13) Taher, M.; Aminuddin, A.; Susanti, D.; Aminudin, N. I.; On, S.; Ahmad, F.; Hamidon, H. Nat. Prod. Sci. 2016, 22, 122-128.

(14) Takeda, K.; Sakurawi, K.; Ishii, H. Tetrahedron 1972, 28, $3757-$ 3766.

(15) Zhao, Y.; Guo, Y. W.; Zhang, W. Helv. Chim. Acta 2005, 88, 349353.

(16) Tanaka, H.; Nakamura, T.; Ichino, K.; Ito, K.; Tanaka, T. Phytochemistry 1990, 29, 857-859.

(17) Ham, Y. M.; Ko, Y. J.; Song, S. M.; Kim, J.; Kim, K. N.; Yun, J. H.; Cho, J. H.; Ahn, G.; Yoon, W. J. J. Funct. Foods 2015, 13, 80-88.

(18) Cao, H. Q.; Lee, B. M.; Jung, Y. W.; Nguyen, V. T.; Kim, J. A.;
Min, B. S. Nat. Prod. Commun. 2017, 12, 259-260.

(19) Shin, M.; Lee, B. M.; Kim, O.; Tran, H. N. K.; Lee, S.; Hwangbo, C.; Min, B. S.; Lee, J. H. Food Funct. 2018, 9, 3895-3905.

(20) Bold, R. J.; Termuhlen, P. M.; McConkey, D. J. Surg. Oncol. 1997, 6, 133-142.

(21) Yang, H. L.; Chen, C. S.; Chang, W. H.; Lu, F. J.; Lai, Y. C.; Chen, C. C.; Hseu, T. H.; Kuo, C. T.; Hseu, Y. C. Cancer Lett. 2006, 231, $215-$ 227.

(22) Kamesaki, H. Int. J. Hematol. 1998, 68, 29-43.

(23) Park, J. H.; Noh, T. H.; Wang, H.; Kim, N. D.; Jung, J. H. Nat. Prod. Sci. 2015, 21, 282-288.

Received May 15, 2018

Revised September 10, 2018

Accepted September 17, 2018 